(C) 2020, The Authors. Published by FASS Inc. and Elsevier Inc. on behalf of the American Dairy Science Association ${ }^{\circledR}$. This is an open access article under the CC BY-NC-ND license (http://creativecommons.org/licenses/by-nc-nd/4.0/).

\title{
In vitro gas production and rumen fermentation profile of fresh and ensiled genetically modified high-metabolizable energy ryegrass
}

\author{
S. Winichayakul, ${ }^{1 *} \odot$ Z. Beechey-Gradwell, ${ }^{1}$ S. Muetzel, ${ }^{1}$ G. Molano, ${ }^{1}$ T. Crowther, ${ }^{1}$ S. Lewis, ${ }^{2}$ H. Xue, ${ }^{1}$ \\ J. Burke ${ }^{3}$ G. Bryan, ${ }^{1}$ and N. J. Roberts ${ }^{1}$ \\ ${ }^{1}$ AgResearch Limited, Palmerston North 4442, New Zealand \\ ${ }^{2}$ Ministry for Primary Industries, Wellington 6140, New Zealand \\ ${ }^{3}$ School of Agriculture and Environment, Massey University, Palmerston North 4442, New Zealand
}

\begin{abstract}
We previously generated a high-metabolizable energy (HME) perennial ryegrass (Lolium perenne) by genetically modifying the plant to increase the leaf lipid content. Although substantial progress has been made toward characterizing physiological changes of HME ryegrass, very limited information exists for feeding value and its suitability for adoption into the pastoral system. In this study, independent HME ryegrass lines with a range of elevated leaf lipid concentrations were analyzed for changes in fatty acids and possible associated changes in the broader nutritional profile, including the gross energy, which was found to increase by $6.8 \%$. Because ryegrass is often ensiled and fermentation in the rumen leads to biohydrogenation of fatty acids as well as enteric methane production, we sought to investigate these effects on HME ryegrass. This was achieved by performing mini-scale silos and using an automated gas measurement system to incubate the material in rumen fluid in vitro for $24 \mathrm{~h}$. Our study included treatments comprising 3 independent HME ryegrass genotypes and wild-type control materials prepared fresh and as silage, employing in total 5 incubation studies, using rumen fluids collected from 4 nonlactating Jersey $\times$ Holstein cows. At intervals during the incubation, the production of gases, volatile fatty acids, and the degree of biohydrogenation were measured. Statistical data analysis indicated that differences in the nutritional compositions of the ensiled materials largely reflected those of their fresh counterparts. Incubation of both fresh and ensiled HME ryegrass in rumen fluid resulted in: (1) a greater percentage of valuable unsaturated fatty acids compared with the control; (2) a significant reduction of butyrate; and (3) a 10 to $15 \%$ decrease in the methane proportion of the total gas production.
\end{abstract}

Received April 10, 2019.

Accepted November 14, 2019.

*Corresponding author: somrutai.winichayakul@agresearch.co.nz
We conclude that ensiling could be a convenient option for preserving HME as a locally produced high-value supplementary feed; however, large-scale application needs to be investigated. In this paper we discuss the potential use of HME ryegrass to enhancing forage feeding value and the potential environmental benefits to the pastoral agriculture industry.

Key words: high-metabolizable energy ryegrass, cysteine-oleosin, methane production, rumen fermentation

\section{INTRODUCTION}

High-metabolizable energy (HME) technology was developed to increase leaf lipid and energy contents (Winichayakul et al., 2013; Roberts et al., 2015), taking into account that (1) lipids contain more Joules per gram than do carbohydrates or proteins and (2) lipid supplementation of ruminant diets reduces methane $\left(\mathrm{CH}_{4}\right)$ production and improves the fatty acid (FA) composition of meat and milk (for review see Rasmussen and Harrison, 2011; Bayat et al., 2018; Haque, 2018). Substantial progress has been made toward characterizing how HME technology influences ryegrass metabolism, with changes including increased photosynthesis and biomass production under a variety of environmental conditions (Beechey-Gradwell et al., 2018). However, the suitability of HME ryegrass for adoption into the pastoral system and its feeding value remain largely unknown.

Microbial biohydrogenation of FA is the primary reason why meat and dairy products are a major source of saturated fats in the human diet, whereas ruminant dietary forage FA are predominantly PUFA. Moreover, products from animals fed silage-based diets typically contain even lower levels of PUFA than products from animals fed fresh forage (Dewhurst et al., 2006; Halmemies-Beauchet-Filleau et al., 2013). There are well-established human health benefits of certain FA, which are found in high levels in ruminant products 
(Shingfield et al., 2013). Specifically, the biohydrogenation intermediates CLA and trans-vaccenic acid (TVA) have been targeted as desirable FA flowing from the rumen into animal tissues (Lourenço et al., 2010; Ghazani and Marangoni, 2016; Toral et al., 2018). Accordingly, various efforts, including lipid supplementation into animal diets, have been made to manipulate and reduce complete biohydrogenation of $\mathrm{FA}$ in the rumen (Jenkins and Bridges, 2007; McKain et al., 2010).

Feeding forages supplemented with plant or fish oil typically increases the molar proportion of the rumen VFA propionate, with concomitant reductions in butyrate and acetate (Dong et al., 1997; Ueda et al., 2003). Ensiled forages have high lactic acid contents, and their ingestion typically results in an increase in the molar proportion of rumen propionate, the main end product of rumen microbial lactic acid fermentation (Sharp et al., 1994; Jalč et al., 2009). However, variable losses of volatile silage components occur during the process of ensiling (before in vitro analyses), which can influence the rumen fermentation pattern, feed utilization, energy partitioning, milk composition, and enteric methane production (Alomar et al., 1999; France and Dijkstra, 2005). Given that the practices of lipid supplementation and ensiling influence the FA profile, the molar proportions of VFA, and $\mathrm{CH} 4$ production, we evaluated these fermentation parameters for HME ryegrass using an in vitro rumen fermentation system. We determined the nutritional composition of HME ryegrass before and after the ensiling process, and investigated changes in the dynamics of biohydrogenation, VFA, total gas, and $\mathrm{CH}_{4}$ production. These experiments were conducted using small quantities of ryegrass grown in a controlled environment, small-scale model silos (Hoedtke and Zeyner, 2011), and in vitro rumen incubation methods (Muetzel et al., 2014).

\section{MATERIALS AND METHODS}

\section{Plant Material and Growth Conditions}

Three independent $T_{0}$ generations of HME transgenic ryegrass lines (HME1, HME2, and HME3) and a wild-type control (WT) were vegetatively propagated into 2-L pots, generating multiple isogenic clones of each. Transgenic lines were selected because they represented a range of leaf $\mathrm{FA}$ profiles and total leaf FA content. First, 8 vegetative clones of HME1, HME3, and WT were grown in a containment glasshouse, and the material was subsequently harvested and used in 2 in vitro rumen incubation runs, as will be described. Later, 8 vegetative clones of HME1, HME2, and WT were grown in a controlled environment room $\left(22^{\circ} \mathrm{C}, 65\right.$ to $70 \%$ humidity, 10-h daylight intensity of 500 to 1,000 $\mu \mathrm{mol} / \mathrm{m}^{2}$ per s) for a fresh versus ensiled material comparison, and subsequently harvested and used in 3 in vitro rumen incubation runs. Pots were rotated along the bench every 2 to $3 \mathrm{~d}$ to provide uniform exposure to the growth conditions. All plant material was defoliated to $6 \mathrm{~cm}$ above the potting medium surface every $3 \mathrm{wk}$.

\section{Harvest and Mini-Scale Ensiling}

Following 2 to 3 cycles of mechanical defoliation, 3 to $4 \mathrm{wk}$ of accumulated regrowth was harvested from $6 \mathrm{~cm}$ above the potting medium surface. Leaf material from 2 plants were pooled to generate enough material for further processing. This resulted in 4 biological replicates of each plant treatment before the incubations and nutritional analyses. Each replicate was thoroughly mixed, and a 10-g subsample was immediately frozen in liquid nitrogen and stored at $-80^{\circ} \mathrm{C}$. The remaining material was wilted overnight at $28^{\circ} \mathrm{C}$ to approximately $50 \%$ of its fresh weight (corresponding to approximately $30 \%$ DM). The wilted material was thoroughly mixed and chopped into 2- to 4-cm lengths. Preliminary analyses revealed that ryegrass grown under artificial lighting contained an insufficient leaf water-soluble carbohydrates (WSC) concentration (approximately 5 to $10 \%$ DM) to support rapid lactic acid silage fermentation (Seale et al., 1986). Therefore, to promote our ensiled fermentation, the wilted plant material was inoculated with a solution of lactic acid bacteria (Ecosyl MTD/1 inoculant, Ecosyl Products Inc., Byron, IL; $1.54 \times 10^{11}$ $\mathrm{cfu} / \mathrm{g}$ ) and a $2 M$ glucose solution, which was applied at a rate that increased the effective WSC concentration of the pre-ensiled ryegrass to approximately 12.5 to $17.5 \%$ dry weight (DW). Both solutions were sprayed onto the chopped ryegrass, and the rates of application by weight were monitored to ensure uniform application. Approximately $30 \mathrm{~g}$ of plant material per replicate silage packet was placed into an ordinary plastic bag (code 57441, Elldex, Christchurch, New Zealand) and compressed by hand into a spherical shape. The bags were placed into a $20 \times 15-\mathrm{cm}, 130-\mu \mathrm{m}$-thick vacuum bag (Munro, Food Vacuum Sealers, Bulahdelah, NSW, Australia), from which air was evacuated with a vacuum packer (V.350, Lava GmbH and Co. KG vacuum package, Bad Saulgau, Germany). The vacuum reached the $5-\mathrm{kPa}$ vacuum setting before heat sealing. Silage packets were kept at room temperature for $45 \mathrm{~d}$ and then stored at $-80^{\circ} \mathrm{C}$ until further chemical analyses. Before chemical analyses, silage packets were defrosted for 1 to $2 \mathrm{~h}$, and the contents were thoroughly mixed to ensure that effluent was distributed throughout the ensiled mass. Half of each silage content was taken, 
freeze-dried for $3 \mathrm{~d}$, homogenized to powder, and stored at $-80^{\circ} \mathrm{C}$ until analyzed.

\section{In Vitro Rumen Incubation and Gas Determination}

The plant material previously described was used for in vitro digestion experiments comparing the influences of the genetic modification and the post-harvest treatment. In all incubations, material from 2 biological replicates were used. Moreover, each in vitro digestion experiment was run in duplicate, using rumen fluid collected from 2 independent pasture-fed fistulated cows (nonlactating Jersey $\times$ Holstein). Rumen fluid samples were placed in a prewarmed insulated flask, then transported to the laboratory. Rumen fluid was collected before morning feeding, to reduce variability between incubations (Muetzel et al., 2014). The contents were squeezed through 1 layer of cheesecloth, then mixed with a reduced and prewarmed buffer, as described by Mould et al. (2005), at a ratio of 1:4 under continuous $\mathrm{CO}_{2}$ flushing. After equilibrating the solution with $\mathrm{CO}_{2}$, a $60-\mathrm{mL}$ aliquot of rumen fluid-buffer mixture was added to $125-\mathrm{mL}$ incubation bottles containing 0.6 $\mathrm{g}$ DW of the leaf materials. Incubation of $10 \mathrm{mg}$ DW of substrate per $\mathrm{mL}$ of rumen fluid buffer solution is a standard practice in most batch culture systems, with the exception of the Hohenheim gas test, which uses less feed (Menke et al., 1979; Mauricio et al., 1999; Pellikaan et al., 2011). Bottles were closed with a butyl rubber stopper, mixed well, and randomly placed in an incubator at $39^{\circ} \mathrm{C}$ and connected to the gas measurement system via a 23-g needle. Gas production and composition were recorded automatically every minute, using the system described by Muetzel et al. (2014). Based on fermentation and biohydrogenation kinetics, samples were collected at 1, 3, 6, 10, and $24 \mathrm{~h}$ of incubation from a separate set of incubation bottles. Samples were collected using a $3-\mathrm{mL}$ syringe via a $16-\mathrm{g}$ needle connected to a manual valve. At each time point of the incubation, approximately $0.75 \mathrm{~mL}$ and $0.9 \mathrm{~mL}$ of fermentation material was taken for FA and VFA analysis, respectively, and stored at $-20^{\circ} \mathrm{C}$ until further analysis (Muetzel et al., 2014). Three incubations were performed for the fresh and ensiled material from the controlled environment room, and 2 incubations were performed for the fresh material from the containment glasshouse. To test whether the effects observed in HME are due to the increased lipid content, we also compared the gas production and fermentation profiles between HME and plant oil supplementation. This was achieved by mimicking FA composition of the fresh HME3 by adding $10 \mathrm{mg}$ of soybean oil and $15 \mathrm{mg}$ of flaxseed oil to the WT leaf material (WT+PO) immediately before adding rumen fluid to the incubation bottle.

\section{Nutritional Analysis}

Harvested snap-frozen fresh leaf materials were freezedried (Millrock Technology Inc., Kingston, NY) for 4 $\mathrm{d}$, homogenized to powder, and stored at $-80^{\circ} \mathrm{C}$ until further use. In vitro rumen incubation samples taken for FA analysis were freeze-dried for $3 \mathrm{~d}$ before FAME analysis. Samples of FAME were prepared according to Browse et al. (1986). Total FAME profile was quantified and verified by gas chromatography-mass spectrophotometry (Shimadzu, Kyoto, Japan; GC-MS QP2010, BPX70 column, SGE part number 054603; Winichayakul et al., 2008). We extracted WSC from freeze-dried samples in $80 \%$ ethanol (vol/vol) and $\mathrm{H}_{2} \mathrm{O}$ for low- and high-molecular weight WSC, respectively, and analyzed using a colorimetric anthrone assay, as described in Jermyn (1956). The starch residue remaining from the WSC extraction was enzymatically digested with $\alpha$-amylases and amyloglucosidases, and the released glucose was measured with a glucose oxidase-peroxidase reagent (Jermyn 1956). We determined CP, NDF, $\mathrm{ADF}$, and gross energy of freeze-dried material using the internationally accredited, New Zealand-approved nutrition laboratory at Massey University, Palmerston North, New Zealand, using the Dumas method, Tecator Fibertec extraction unit (Foss Analytics, Hillerød, Denmark), and bomb calorimeter (AOAC International, 2012). For the ensiled material, $\mathrm{pH}$ was determined using a pH meter (PHM2200, F-69627, Radiometer Analytical, Lyon, France) from a wet subsample of 5 $\mathrm{g}$ of silage homogenized with $50 \mathrm{~mL}$ of Milli-Q water (Millipore, Merck KGaA, Darmstadt, Germany), as demonstrated by Cherney and Cherney (2003). Fermentation end product concentrations from the silage and in vitro rumen incubation samples [lactic acid, acetic acid, propionic acid, butyric acid, and ammonia $\left(\mathrm{NH}_{3} / \mathrm{NH}_{4}{ }^{+}\right)$] were determined on water extracts from wet subsamples. Lactic acid and VFA concentrations were quantified using a downscaled method modified from Richardson et al. (1989) and analyzed using a Shimadzu GC-2010 Plus with helium ionization detector and a Zebron ZB-5MS $30 \mathrm{~m} \times 0.25 \mathrm{~mm}$ i.d., $0.25-\mu \mathrm{m}$ film capillary column (Phenomenex, Torrance, CA), as described in Attwood et al. (1998). Levels of $\mathrm{NH}_{3} / \mathrm{NH}_{4}{ }^{+}$ were determined using a downscaled method modified from Weatherburn (1967).

\section{Statistical Analysis}

Experiment data were analyzed by 1-way or 2-way ANOVA using R3.6.1 software (CRAN.R-project.org, Institute of Statistics and Mathematics, WU, Wien, Austria) with a model that included fixed effect of ryegrass genotypes (HME and WT) and ensilage (fresh 
and ensiled materials). In some cases, a log or square root transformation was applied to the responses for matching the normality assumption of ANOVA. A multiple comparison of predicted means from ANOVA was used to highlight significance among treatment means, and $P$-values were adjusted using the $\mathrm{BH}$ method (Benjamini and Hochberg, 1995) to control the false discovery rate. Data were analyzed using the Kruskal Wallis test (Conover, 1999) with multiple comparison of treatments when responses appeared with highly skewed distribution, and $P$-values were calculated from chi squared. Means and least significant differences are reported, and fixed effects declared significant at $P \leq$ 0.05 , whereas a tendency was assumed for $0.05 \leq P \leq$ 0.10 . No effect on incubation due to different rumen fluids was observed. When the overall effect of treatment was significant, mean comparisons were further tested using Tukey's test.

\section{RESULTS}

\section{Composition of Fresh and Ensiled Material}

The chemical compositions of freshly harvested and ensiled WT and HME ryegrass grown in a controlled environment room are shown in Table 1. The DM content of the fresh HME ryegrass was slightly lower than that of the fresh WT ryegrass $(P=0.002)$. Total FA content was greatly increased by 59 to $66 \%$ in HME lines, relative to WT $(P<0.01)$. The concentrations of all FA classes were greater in the HME lines than WT $(P<0.05)$. However, as a proportion of total FA, we found increases in C18:1, C18:2, C20:1, C22:0, and $\mathrm{C} 22: 1$, and reductions in $\mathrm{C} 16: 0, \mathrm{C} 16: 1$, and $\mathrm{C} 18: 3(P<$ $0.05)$. Similar differences in FA content were observed between fresh WT and HME plants grown in a containment glasshouse, including HME line 3 (98\% increased total FA), although we did not detect $\mathrm{C} 22: 1$ in ryegrass grown in a containment glasshouse (Tables 1 and 2). We found no difference $(P>0.10)$ between WSC in fresh HME1 and WT grown in a controlled environment room (Table 1), but WSC decreased by $16 \%$ in fresh HME1 $(P<0.001)$ when the plants were grown in a containment glasshouse (Table 2). Compared with the control WT, WSC content was decreased by 15 and $24 \%$ in fresh HME2 (controlled environment, $P=$ 0.003 ) and HME3 (containment glasshouse, $P<0.001$ ), respectively. We observed small differences in other components of the fresh HME compared with WT, such as starch $(P>0.10)$, total $\mathrm{CP}(P=0.055)$, and elevated fiber $(P=0.028$ for $\mathrm{NDF}$, and $P=0.066$ for ADF). Gross energy was increased by approximately $6.8 \%$ in HME1 and 6\% in HME2, relative to WT $(P \leq$ $0.0001)$.
After $45 \mathrm{~d}$ of ensiling, the nutritional compositions of WT, HME1, and HME2 silage (Table 1) generally reflected those of the freshly harvested materials. We found small change of FA due to our ensiling process, with statistical significance at $P<0.05$. A major change to the FA profile of WT during the ensiling process was the reduction of C18:1 $(33 \%, P<0.001)$ and the increase of C16:1 (29\%, $P<0.001)$. Given that C18:1 and C16:1 represent only a small proportion of total FA in WT, the changes during ensiling did not affect the proportions of other FA. Changes to the FA profile of HME during ensiling were less than in WT (with the greatest being a $9 \%$ reduction of $\mathrm{C} 18: 1, P$ $<0.001)$. Therefore, compared with WT, both fresh and ensiled HME material had greater total FA content, higher proportions of C18:0, C18:1, C18:2, C20:1, $\mathrm{C} 22: 0$, and $\mathrm{C} 22: 1$, and reduced proportions of $\mathrm{C} 16: 0$, $\mathrm{C} 16: 1$, and $\mathrm{C} 18: 3$.

Both WSC and starch were greatly decreased during ensiling (Table 1). We found a very small $\mathrm{pH}$ difference between HME1 and WT silage (but not HME2, $P=$ $0.061)$ and no difference in $\mathrm{NH}_{3} / \mathrm{NH}_{4}^{+}$content $(P>$ 0.10). Compared with WT, both ensiled HME1 and HME2 trended to contain less lactate, acetate, and succinate than did the ensiled WT $(0.05 \leq P \leq 0.10)$ but only statistical difference in acetate of HME2 silage $(P$ $=0.039$, Table 1$) ;$ propionate and butyrate were not detected.

\section{Influence of Rumen Fluid Incubation on FA Saturation}

To evaluate rumen biohydrogenation, we analyzed the FA composition of the HME and WT, in both fresh and ensiled forms, at 5 time points $(1,3,6,10$, and $24 \mathrm{~h}$ ) during the in vitro rumen incubation (Table 3 ). Generally, a greater proportion and quantity of UFA were detected when both fresh and ensiled HME ryegrass were incubated, compared with WT throughout a 24-h incubation $(P<0.05)$. Compared with WT, both fresh and ensiled HME showed a trend of greater quantity of C18:3 n-3 and C18:2 n-6 (0.05 $\leq P \leq 0.10)$, and the differences were more significant in the silage $(P<0.05)$. Greater amounts of $\mathrm{C} 18: 3 \mathrm{n}-3$ and $\mathrm{C} 18: 2 \mathrm{n}$ -6 were detected in the ensiled HME than in their fresh counterparts during 1 - to 6 -h incubation $(P<0.05)$. Incubation of fresh material appeared to predominantly produce greater amounts of CLA (between 1 and $3 \mathrm{~h}$ ) and TVA (between 3 and $6 \mathrm{~h}$, not the WT) than did the ensiled material. Between 6 and $24 \mathrm{~h}$, both fresh and ensiled HME in rumen fluid contained greater amounts of CLA and TVA than did the WT $(P<0.01)$. Incubation of both fresh and ensiled HME produced greater amounts of $\mathrm{C} 18: 1$ cis-9 than did the WT $(P<0.05)$, 
Table 1. Dry matter and compositions of fresh and ensiled ryegrass grown in a controlled environment room ${ }^{1}$

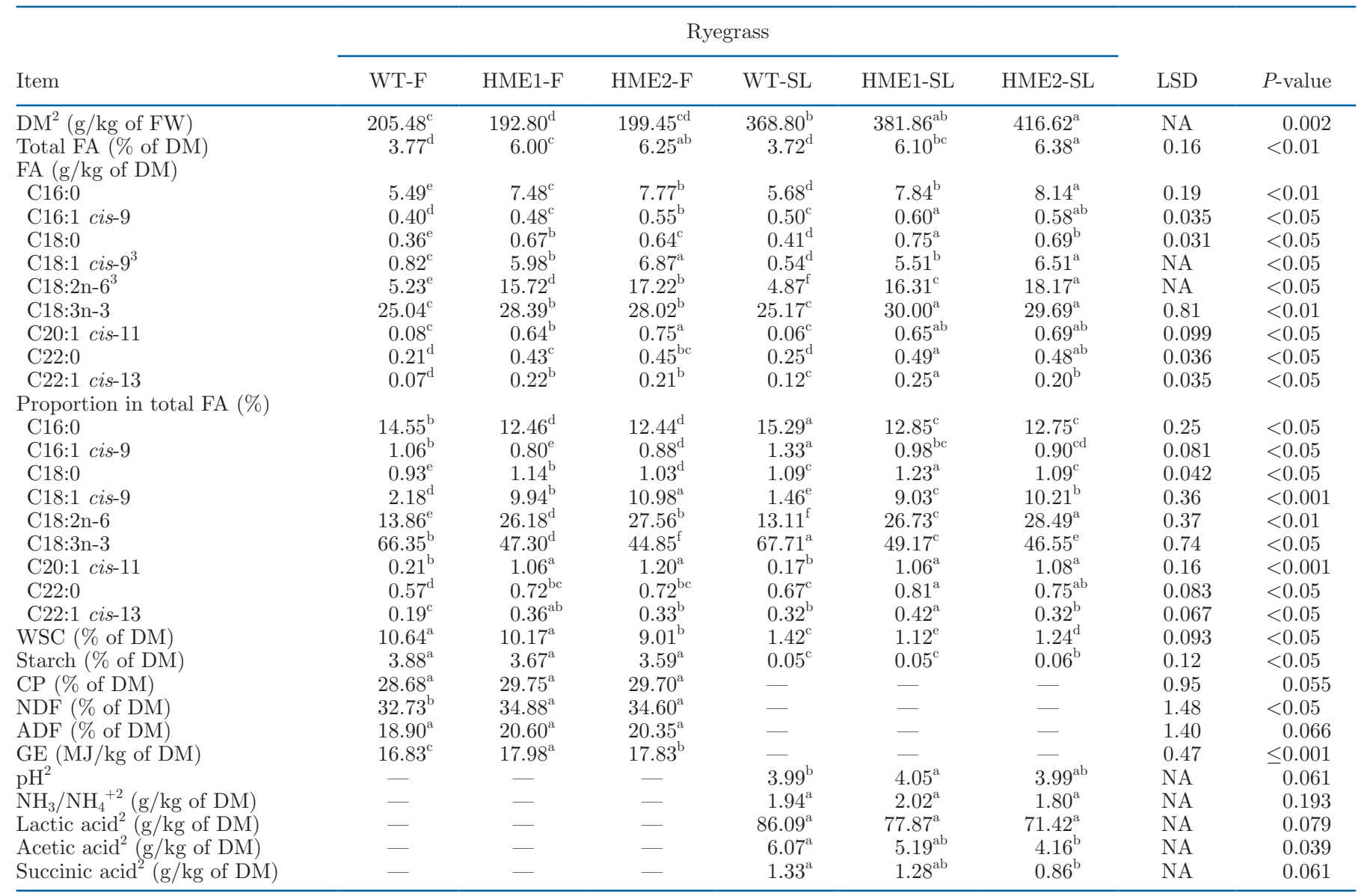

${ }^{\mathrm{a}-\mathrm{f}}$ Means within a row with different superscripts differ $(P<0.05)$.

${ }^{1} \mathrm{WT}=$ wild-type ryegrass; HME $=$ high-metabolizable energy ryegrass; $\mathrm{F}=$ fresh; $\mathrm{SL}=$ silage; FA $=$ fatty acids; WSC $=$ water-soluble carbohydrates; $\mathrm{GE}=$ gross energy; $\mathrm{NH}_{3} / \mathrm{NH}_{4}^{+}=$ammonia; $-=$analysis not performed; $\mathrm{NA}=$ not available.

${ }^{2}$ Data were analyzed using Kruskal-Wallis test with multiple comparison of treatments.

${ }^{3}$ Data were analyzed using log transformation.

but we found no difference of C18:1 cis-9 between fresh and their corresponding ensiled materials. We observed no difference of $\mathrm{C} 18: 0$ among treatments at each time point $(P>0.10)$.

We also compared the degree of FA biohydrogenation in HME ryegrass with exogenous lipid supplementation to simulate FA profile of the HME. This was achieved by analyzing the FA profiles of a containment glasshouse grown WT, WT supplemented with plant oil at $3.7 \%$ of ryegrass DW (WT+PO; see Table 2 for composition), and fresh HME1 and HME3 (plants grown in the same containment glasshouse as WT) at various time points during the in vitro rumen incubation (Table 4). Compared with the WT, although both WT+PO and HME had higher quantities of UFA throughout the 24-h incubation in rumen fluid, incubation of HME contained slightly but significantly greater UFA than did $\mathrm{WT}+\mathrm{PO}(P<0.05)$. Rumen incubation of HME3 showed less biohydrogenation of $\mathrm{C} 18: 3 \mathrm{n}-3$ than did the $\mathrm{WT}+\mathrm{PO}$ during 24 -h incubation $(P<0.01)$, except at $10 \mathrm{~h}(P>0.10)$. We found that $\mathrm{C} 18: 2 \mathrm{n}-6$ were higher in the incubation of WT+PO than that of HME3 during 1 to $3 \mathrm{~h}(P<0.01)$, not different at $6 \mathrm{~h}(P>0.10)$, and less during 10 to $24 \mathrm{~h}(P<0.001)$. Although both $\mathrm{WT}+\mathrm{PO}$ and HME produced more CLA and TVA than did the WT, rumen incubation of HME3 had greater amount of TVA during 1 to $10 \mathrm{~h}$ than did WT+PO $(P$ $<0.05)$. Rumen incubation of HME3 showed less C18:1 cis-9 $(P<0.001$, no different at $1 \mathrm{~h})$ and less $\mathrm{C} 18: 0(P$ $<0.05)$ than that of $\mathrm{WT}+\mathrm{PO}$.

Generally, we found similar trends of FA profiles between the in vitro incubations of plant materials harvested from 2 growth conditions (controlled room and glasshouse, Table 3 and Table 4). However, we 
noted that incubation of the plant materials from the glasshouse showed differences of C18:3n-3 $(P<0.01)$ and C18:0 $(P<0.01)$ between WT and HME1 but no significant difference from the controlled room plant materials $(P>0.10)$.

\section{Influence of Rumen Fluid Incubation on VFA Concentration}

The concentrations of total VFA increased in all incubations throughout the $24 \mathrm{~h}$. We detected some small differences between the WT and HME incubations at 10 and $24 \mathrm{~h}$, but the trends and magnitudes were similar (Table 5). Irrespective of whether the incubated material was fresh or ensiled, the proportion of acetate produced from the HME incubation increased slightly (between 3 and $24 \mathrm{~h}, P<0.05$ ), whereas propionate was not markedly changed, and butyrate decreased $(P<0.05)$, compared with their corresponding WT. Compared with the corresponding fresh material, the proportion of acetate produced from silage incubation of both HME and WT was reduced (between 6 and 24 h), whereas butyrate (and the other VFA for only at the end of incubation) was greater. The other incubations of
HME1 and HME3 fresh material from the containment glasshouse-grown plants confirmed the results (Table 6 ). The proportion of acetate produced from incubation of fresh HME1 and HME3 was slightly increased only between 10 and $24 \mathrm{~h}(P=0.057)$, whereas no change in propionate occurred, and butyrate decreased significantly between 6 and $24 \mathrm{~h}(P<0.001)$. There was no difference in either production or proportion of VFA from the incubation of WT+PO to the WT.

\section{Influence of Rumen Fluid Incubation on Total Gas and $\mathrm{CH}_{4}$ Production}

To evaluate the influence of $\mathrm{HME}$ on $\mathrm{CH}_{4}$ production, we measured total gas and $\mathrm{CH}_{4}$ production from the in vitro rumen incubations. Compared with fresh WT material, incubation of ensiled WT showed a reduction of total gas production and unchanged production of $\mathrm{CH}_{4}$. This resulted in an increase in the proportion of $\mathrm{CH}_{4}$ produced from the incubation of ensiled material compared with fresh (Figure 1). In contrast, incubation of ensiled HME material showed increased total gas and $\mathrm{CH}_{4}$ production compared with the respective fresh material. However, like the WT, this resulted in a

Table 2. Fatty acid, water-soluble carbohydrate, and starch compositions of ryegrass material harvested from plants grown in a containment glasshouse

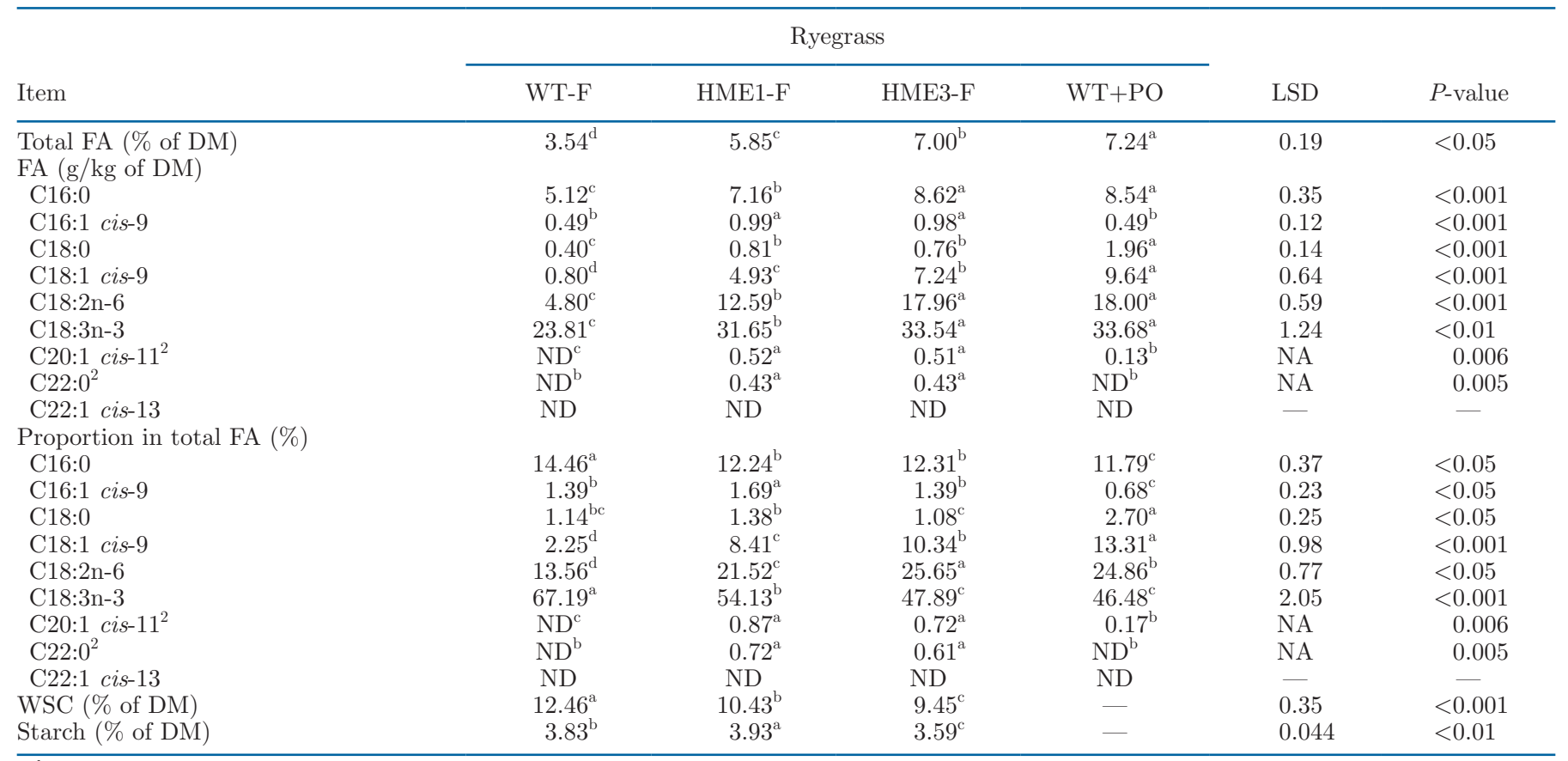

${ }^{\mathrm{a}-\mathrm{d}}$ Means within a row with different superscripts differ $(P<0.05)$.

${ }^{1} \mathrm{WT}=$ wild-type ryegrass; $\mathrm{HME}=$ high-metabolizable energy ryegrass; $\mathrm{F}=$ fresh; $\mathrm{WT}+\mathrm{PO}=\mathrm{WT}$ supplemented with $3.7 \%$ plant oil to mimic FA content of HME3; $\mathrm{FA}=$ fatty acids; $\mathrm{WSC}=$ water-soluble carbohydrates; - = analysis not performed; $\mathrm{NA}=$ not available; $\mathrm{ND}=$ not detected.

${ }^{2}$ Data were analyzed using Kruskal-Wallis test with multiple comparison of treatments. 
greater proportion of $\mathrm{CH}_{4}$ production from the ensiled than the fresh material; thus, silage from either WT or HME resulted in an increased proportion of $\mathrm{CH}_{4}$ produced. Compared with the WT, both fresh and ensiled HME material showed reductions in total gas (approximately $22 \%$ for fresh, $<5 \%$ for silage) and $\mathrm{CH}_{4}$ (approximately $30 \%$ for fresh, $15 \%$ for silage) production (Figure 1). This resulted in approximately 10 and 10 to $15 \%$ (fresh and silage, respectively) decreases in $\mathrm{CH}_{4}$ proportion produced in the HME incubation. Additionally, we compared the gasses produced during the other in vitro rumen incubations of fresh material from the containment glasshouse-grown plants. The results confirmed that incubation of fresh HME material produced less total gas, $\mathrm{CH}_{4}$, and $\mathrm{CH}_{4}$ proportion than did WT (Figure 2). No difference was observed between $\mathrm{WT}+\mathrm{PO}$ and WT from 2 incubations.

\section{DISCUSSION}

In ryegrass the HME technology approximately doubled the leaf lipid content, altered FA profiles, and increased leaf regrowth (Beechey-Gradwell et al., 2018). However, enhancing the content of one nutritional component may result in changes to others; indeed, our results here showed up to a $24 \%$ decrease in WSC but only small changes in starch, total CP, and dietary fiber in fresh HME compared with normal ryegrass. It was interesting that HME influenced the level of WSC, which is thought to be a consequence of shifting the carbon allocation away from reserve carbohydrate accumulation to lipid biosynthesis (Vanhercke et al., 2014). Considering the fundamental role that WSC play in plant energy homeostasis and the influence of the environment on their accumulation, future

Table 3. Fatty acid profiles of fresh and ensiled ryegrass incubated in vitro with rumen fluid ${ }^{1}$

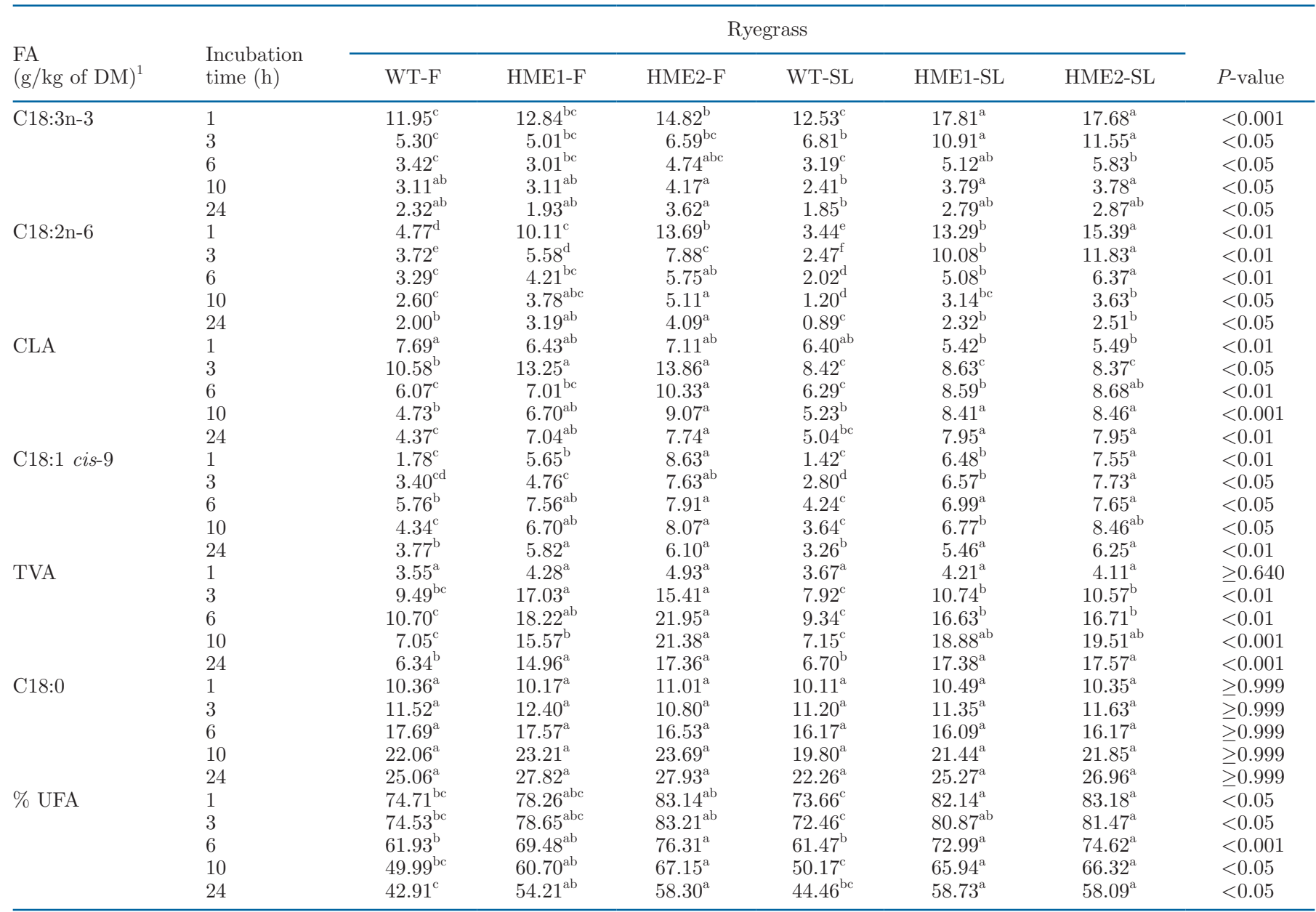

${ }^{\mathrm{a}-\mathrm{f}}$ Means within a row with different superscripts differ $(P<0.05)$.

${ }^{1} \mathrm{WT}=$ wild-type ryegrass; HME $=$ high-metabolizable energy ryegrass; $\mathrm{F}=$ fresh; $\mathrm{SL}=$ silage $; \mathrm{FA}=$ fatty acids; CLA = coelution of C18:2 cis-9,trans-11, C18:2 trans-10,cis-12, C18:2 trans-9,cis-12, and C18:2 cis-9,trans-13; TVA = trans-vaccenic acid (C18:1 trans-11).

${ }^{2}$ Data were analyzed by 2 -way ANOVA. 
experiments should determine whether HME technology affects the WSC content of ryegrass under a variety of growth conditions.

Silage quality refers to a combination of chemical factors related to ensiling $\mathrm{pH}$ and the concentrations of fermentation end products that together indicate how efficiently nutrients have been preserved during the fermentation and storage phases (Cherney and Cherney, 2003; Naoki and Yuji, 2008). By using mini-scale model silos (together with additional lactic acid bacteria and glucose), we converted both HME and WT into wellpreserved silage, as indicated by (1) $\mathrm{pH}$ lower than 4.2 ; (2) lactate-to-acetate ratio greater than $2: 1$; and (3) concentration of butyrate lower than $5 \%$ of DM (Buxton and O'Kiely, 2003). Two major processes can affect lipids and FA during the overall ensiling process:
(1) during the aerobic field-wilting phase, reductions in total FA content and PUFA concentrations occur; (2) during anaerobic fermentation, lipolysis of membrane lipids is extensive, resulting in the majority of FA in silage occurring as free FA, while the FA composition is largely unaffected. The reduction in total FA content due to ensiling in our experiments was less than that of most examples in the literature (Glasser et al., 2013) and may be the result of our rapid artificial small-scale procedures. In the future, it would be interesting to evaluate quality of the HME ryegrass silage made on an industrial scale.

Lipid metabolism in the rumen is characterized by 2 main sequential processes: lipolysis of esterified lipids and hydrogenation of free FA by microbes to saturated end products such as stearic acid (C18:0),

Table 4. Fatty acid profiles of the in vitro rumen incubation of fresh ryegrass material harvested from plants grown in a containment glasshouse ${ }^{1}$

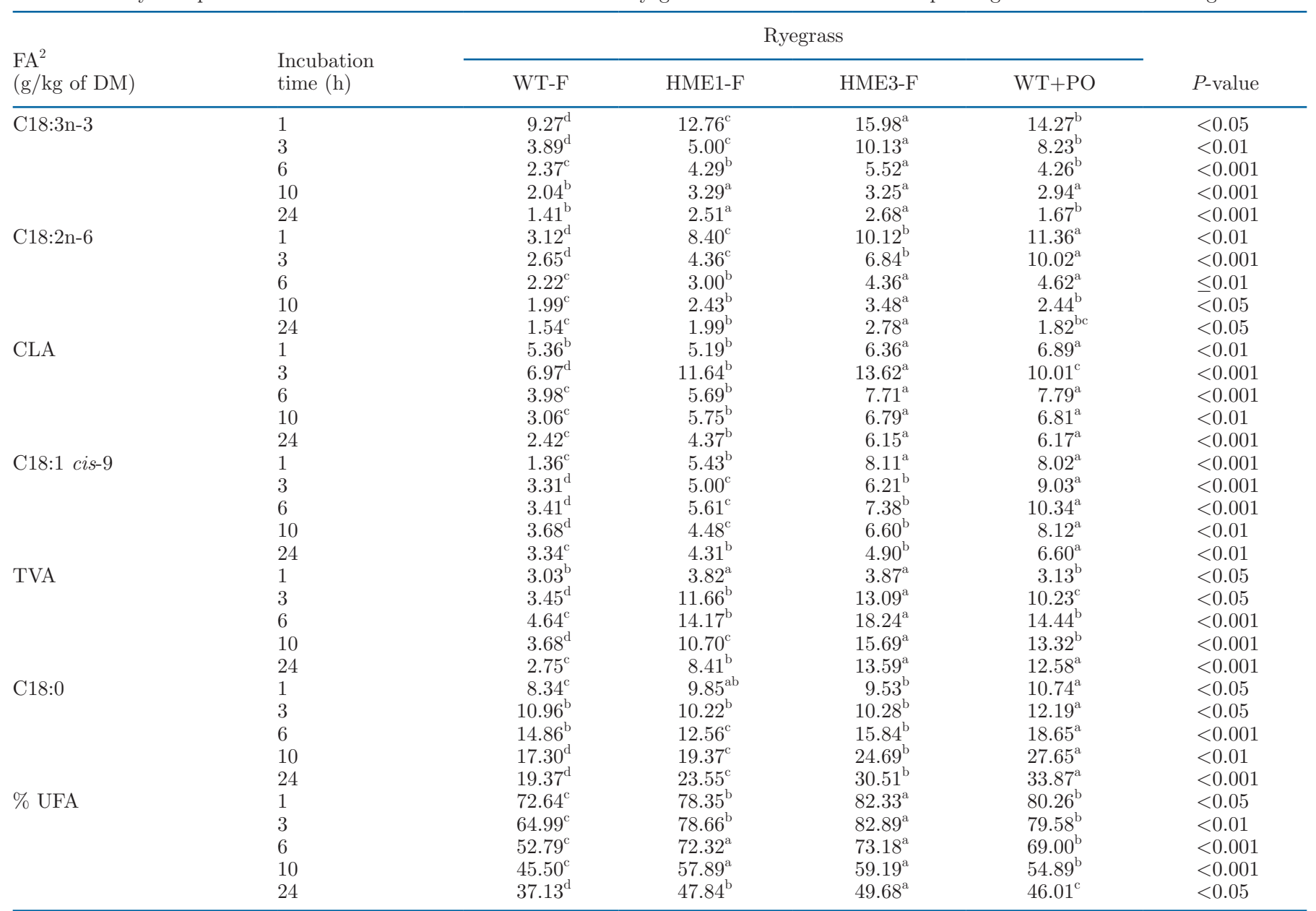

\footnotetext{
${ }^{\mathrm{a}-\mathrm{d}}$ Means within a row with different superscripts differ $(P<0.05)$.
}

${ }^{1} \mathrm{WT}=$ wild-type ryegrass; HME $=$ high-metabolizable energy ryegrass; $\mathrm{F}=$ fresh; $\mathrm{WT}+\mathrm{PO}=\mathrm{WT}$ supplemented with $3.7 \%$ plant oil to mimic FA content of HME3; FA = fatty acids; CLA = coelution of C18:2 cis-9,trans-11, C18:2 trans-10, cis-12, C18:2 trans-9,cis-12, and C18:2 cis9,trans-13; TVA $=$ trans-vaccenic acid $(\mathrm{C} 18: 1$ trans-11).

${ }^{2}$ Data were analyzed by 2-way ANOVA, using square root transformations of variables. 
with a dynamic formation of other C18-FA intermediates (Harfoot and Hazlewood, 1997). Different degrees of biohydrogenation of individual FA have been reported. For most feed sources, 85 to $100 \%$ of C18:3n -3 is rapidly hydrogenated (Doreau and Ferlay, 1994), and this was reliably the case in our in vitro experiments. However, the biohydrogenation rate of $\mathrm{C} 18: 3 \mathrm{n}$ -3 in HME was primarily lower than that of WT until around $6 \mathrm{~h}$. Two potential reasons may explain the initial lower rate of HME FA biohydrogenation, including the higher starting level of PUFA, which are toxic to the rumen microbes (Lourenço et al., 2010). Although HME3 and WT+PO had comparable FA compositions, their biohydrogenation profiles differed. Winichayakul et al. (2013) demonstrated that lipid droplets associated with HME technology (using cysteine-oleosin) are more stable than those associated with oleosin in the presence of either serine or cysteine protease. As such, a contributing factor may lie in partial protection of some UFA in the HME material.

Complete biohydrogenation does not always occur in the rumen, and in our case several trans- and conjugated C18:1 and C18:2 compounds were formed. These included TVA and CLA isomers, which are often present in ruminant products derived from pasture-fed animals (Aharoni et al., 2005). After 24-h incubation the HME and WT+PO samples had higher levels of CLA and TVA than did the WT, which has practical relevance, given that consumption of these UFA and trans-fats may have human health benefits (Banni et al., 2001; Field et al., 2009; Lim et al., 2014). Animal feeding trials of HME ryegrass will be required to truly evaluate the potential of high-lipid ryegrass to add value to meat and milk products.

Incubation of silage (both HME and WT) in rumen fluid resulted in lower proportions of acetate and higher proportions of butyrate compared with their fresh counterparts, in agreement with earlier reports (Jaakkola and Huhtanen, 1993; Holden et al., 1994; Mohammed et al., 2009). Similar to other lipid supplementation strategies, HME technology did not substantially affect total VFA (less than 8\%) and shifted the fermentation pattern by reducing the molar proportion of butyrate (Jalč et al., 2006). This decrease in butyrate production may be due to the toxicity of free FA to Butyrivibrio (Paillard et al., 2007); however, unlike other lipid supplements, HME had no effect on propionate and caused only a modest effect in acetate.

Table 5. Volatile fatty acids produced from the in vitro incubation of fresh and ensiled ryegrass with rumen fluid ${ }^{1}$

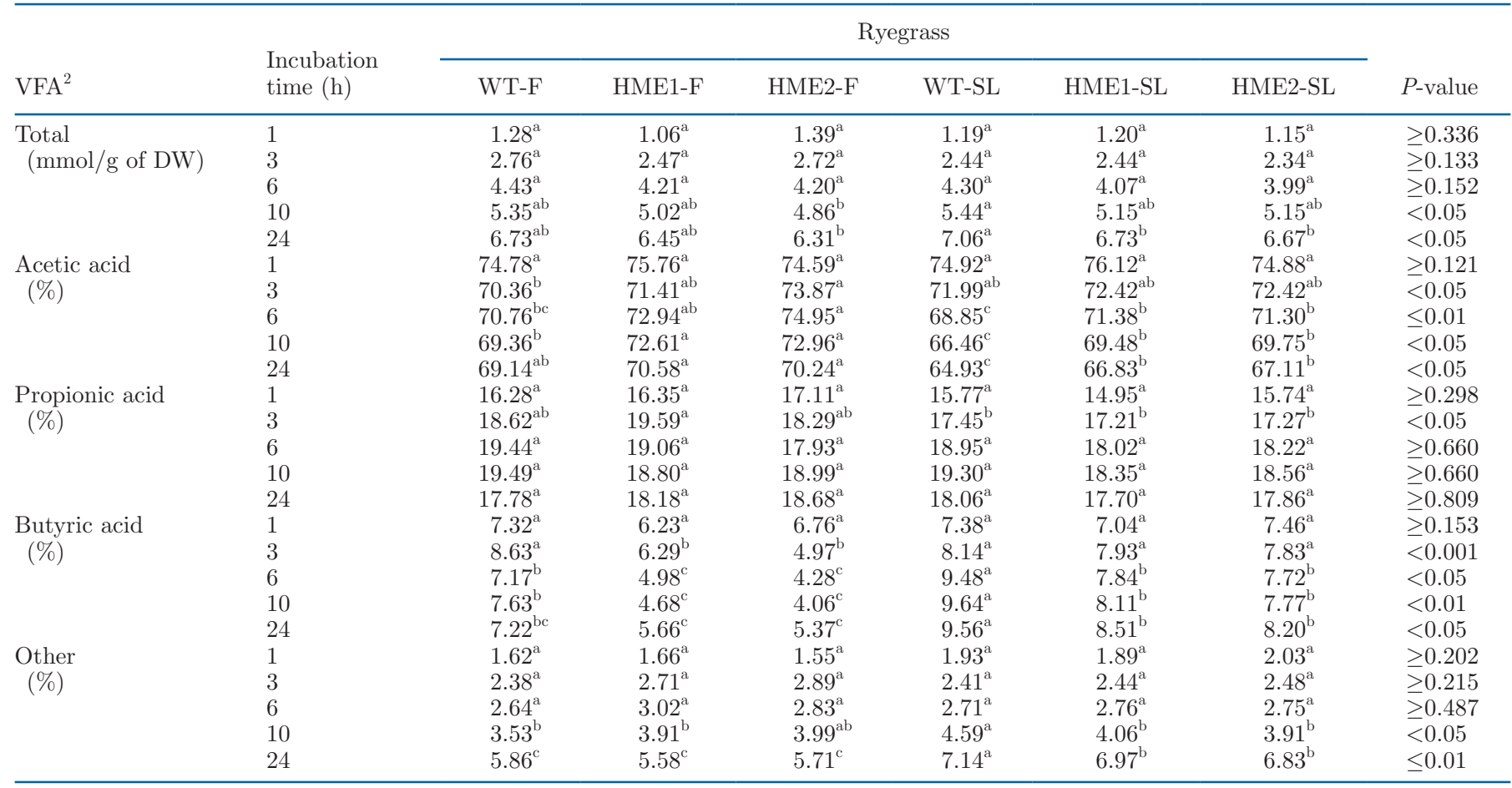

${ }^{\mathrm{a}-\mathrm{c}}$ Means within a row with different superscripts differ $(P<0.05)$.

${ }^{1} \mathrm{WT}=$ wild-type ryegrass; HME $=$ high-metabolizable energy ryegrass; $\mathrm{F}=$ fresh; $\mathrm{SL}=$ silage; DW $=$ dry weight. Other VFA $=$ caproic acid, isobutyric acid, isovaleric acid, and valeric acid.

${ }^{2}$ Data were analyzed via 2-way ANOVA, using square root transformations of variables. 
Table 6. Volatile fatty acids produced from the in vitro rumen incubation of ryegrass material harvested from plant grown in a containment glasshouse $^{1}$

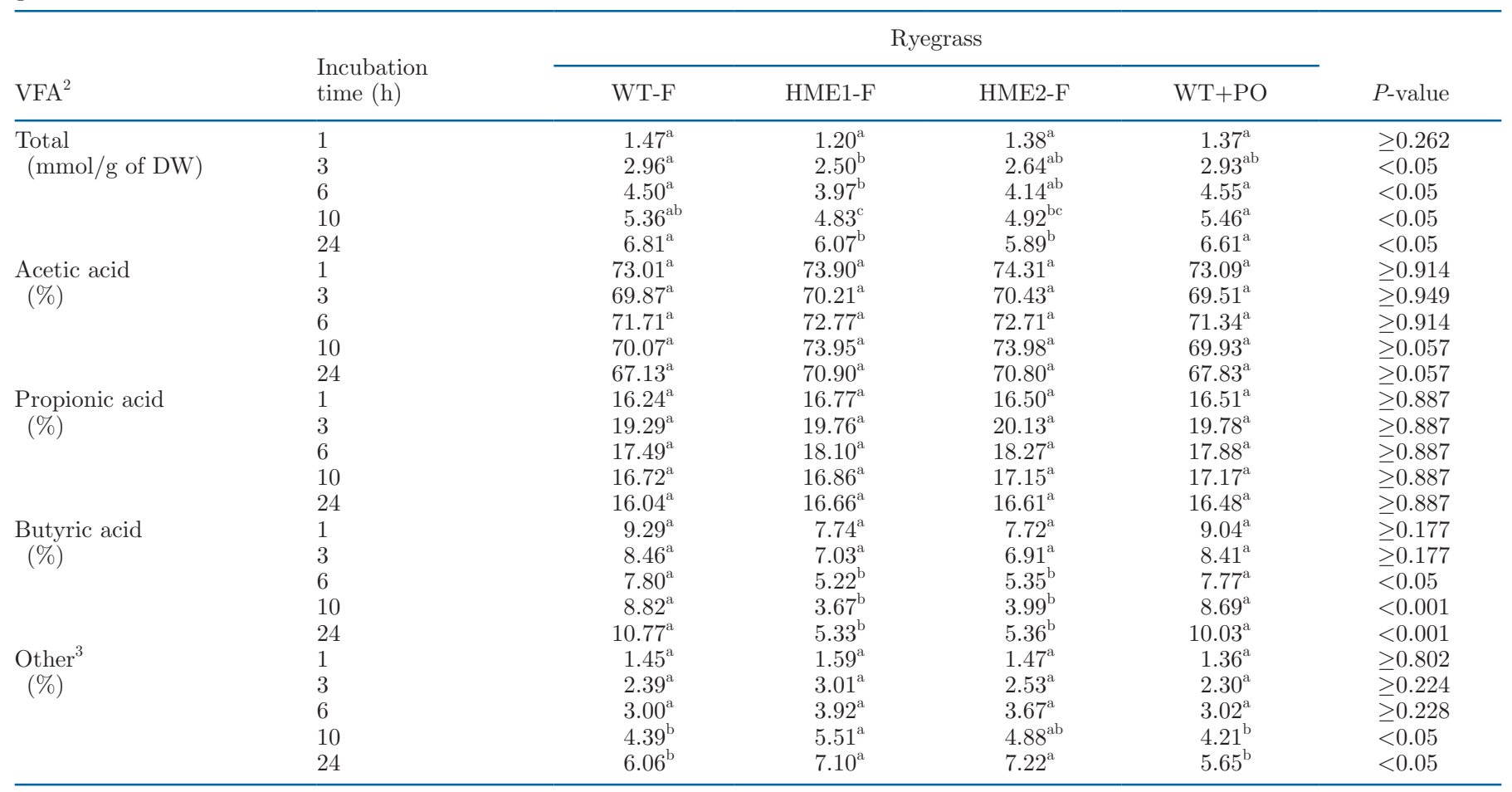

${ }^{\mathrm{a}-\mathrm{c}}$ Means within a row with different superscripts differ $(P<0.05)$.

${ }^{1} \mathrm{WT}=$ wild-type ryegrass; $\mathrm{ME}=$ high-metabolizable energy ryegrass; $\mathrm{F}=$ fresh; $\mathrm{WT}+\mathrm{PO}=\mathrm{WT}$ supplemented with $3.7 \%$ plant oil to mimic fatty acid content of HME3. DW = dry weight.

${ }^{2}$ Data were analyzed via 2-way ANOVA, using square root transformations of variables.

${ }^{3}$ Other VFA = caproic acid, isobutyric acid, isovaleric acid, and valeric acid.

It was estimated by Beauchemin et al. (2008) that for every $1 \%$ increase DW in dietary lipid (up to $8 \%$ maximum) a $5 \%$ decrease would occur in enteric $\mathrm{CH}_{4}$ produced. It is known that lipid supplementation reduces $\mathrm{CH}_{4}$ emissions by (1) inhibition of fermentation activity of methanogenic archaea or rumen bacteria and protozoa (or both) by binding to cell membranes and interrupting membrane transport (Dohme et al., 2001), and (2) biohydrogenation of FA by microbial enzymes, reducing the availability of $\mathrm{H}^{+}$ions for methanogenesis (Johnson and Johnson, 1995). The 10 to $15 \%$ reduction in $\mathrm{CH}_{4}$ produced during 24-h in vitro rumen fluid incubation of HME compared with the WT ryegrass agreed with these reports. However, when lipids were added to the control grass (WT+PO), VFA, total gas, and methane produced were not changed. These results suggested that the effect of HME ryegrass on rumen fermentation may be due not simply to the higher lipid content but to several possibilities in concert, including other compositional differences in HME (e.g., lignin, cellulose, nitrate) yet to be determined (Zhao et al., 2015; Wang et al., 2019).
One of the difficulties of evaluating the influence of supplemental oil is that a proportion of it simply bypasses the rumen to the abomasum, and as such it has no apparent influence on methanogens (Jenkins, 1993). Kong et al. (2010a, b) measured methanogen numbers in the rumen of dairy cows and found no difference in the proportion of these microbial species present when a source of highly unsaturated lipids from ground flaxseed was added. It was suggested that lipid supplementation was affecting fermentation activity instead of methanogen populations. Several studies have reported on the potential differences of $\mathrm{CH}_{4}$ mitigation between individual animal breeds fed with lipid supplemental diets both in vitro and in vivo (Guyader et al., 2015; Veneman et al., 2015; Vargas et al., 2017). Consequently, studies of the rumen microbiota across countries or cattle breeds with lipid supplementation diets may be necessary before lipids can be used as an effective $\mathrm{CH}_{4}$ mitigation strategy. A more detailed nutritional analysis is required to understand how HME ryegrass influences rumen fermentation. Further investigation of rumen microbe communities during 
WT-F OWT-SL HME1-F $\diamond$ HME1-SL $\diamond$ HME2-F $\diamond$ HME2-SL
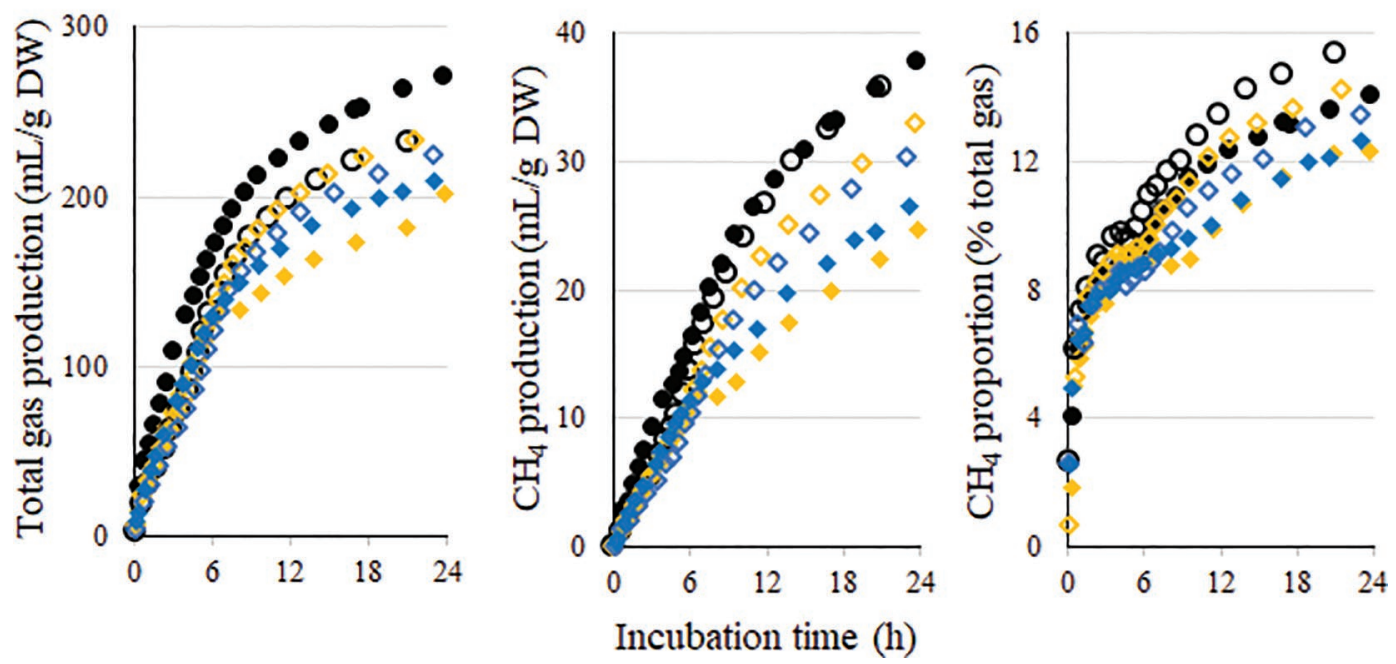

Figure 1. Gas production from the in vitro incubation of fresh (F) and ensiled (SL) high-metabolizable energy (HME) and control wild-type (WT) ryegrass with rumen fluid. Data presented as real-time measurement of total gas produced as $\mathrm{mL} / \mathrm{g}$ of ryegrass DM (DW $=$ dry weight), $\mathrm{CH}_{4}$ gas produced as $\mathrm{mL} / \mathrm{g}$ of ryegrass DM, and $\mathrm{CH}_{4}$ proportion as percentage of total gas production throughout a 24-h incubation. Four biological replicates of each treatment used in 3 in vitro incubations produced similar results.

HME fermentation would also be valuable. Eventually, animal feeding trials of HME ryegrass will be required to truly evaluate the benefit of high-lipid ryegrass to reduce $\mathrm{CH}_{4}$ emission (Henderson et al., 2015).

\section{CONCLUSIONS}

The elevated lipid content in HME ryegrass increased the gross energy content, which could improve animal

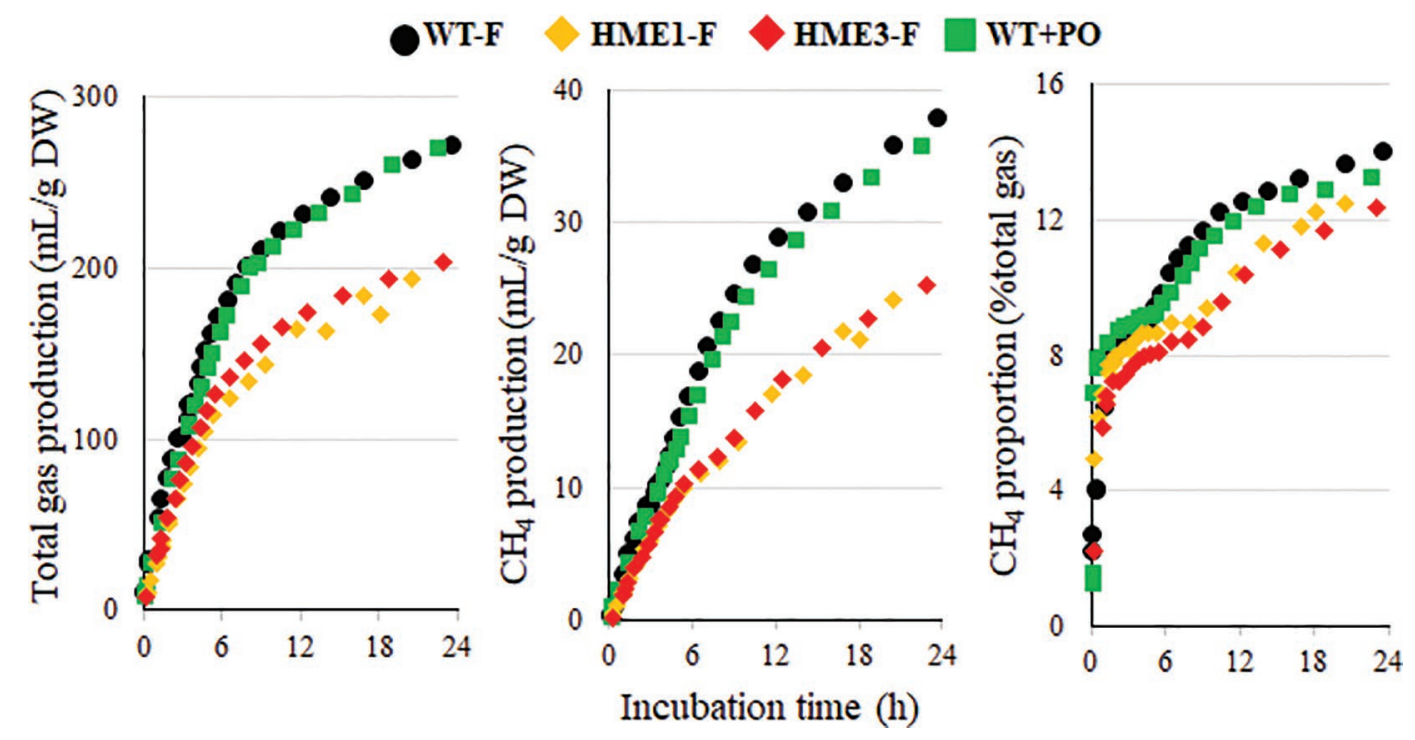

Figure 2. Gas production from the in vitro rumen incubation of fresh (F) high-metabolizable energy (HME) and control wild-type (WT) ryegrass (plants grown in a containment glasshouse), and WT supplemented with $3.7 \%$ plant oil (WT+PO). Data were presented as real-time measurement of total gas produced as $\mathrm{mL} / \mathrm{g}$ of ryegrass $\mathrm{DM}\left(\mathrm{DW}=\right.$ dry weight), $\mathrm{CH}_{4}$ gas produced as $\mathrm{mL} / \mathrm{g}$ of ryegrass $\mathrm{DM}$, and $\mathrm{CH}_{4}$ proportion as percentage of total gas production throughout a 24-h incubation. Four biological replicates for each treatment used in 2 in vitro incubations produced similar results. 
performance and farm profitability. Field trials are being used to determine how HME ryegrass performs outdoors, and how to best manage this technology in pastoral farming systems. In a future scenario where a version of this technology is available to farmers, ensiling could be a convenient option for preserving HME so that it can be used later as a locally produced highvalue supplementary feed. The fatty acid component of HME ryegrass should be well-preserved during anaerobic fermentation; however, farmers may face a tradeoff between the beneficial effects of field-wilting and greater absolute losses of PUFA during an extended aerobic phase (although this did not change in our laboratory-scale wilting experiments). Therefore, the stability of FA from HME ryegrass during an extended aerobic phase should be investigated. A significantly increased proportion of TVA, CLA, and other UFA outflow from the rumen could have positive health implications for human consumption of ruminant-derived products. Further nutritional analysis of HME ryegrass over an extended vegetative regrowth and during the reproductive transition is required to provide insight into how this novel technology should be managed for grazing or ensiling purposes.

\section{ACKNOWLEDGMENTS}

This work was conducted within the framework of contract C10X1603 (Ministry of Business, Innovation and Employment, Wellington, New Zealand). Thanks to Dongwen Luo (AgResearch Ltd., Palmerston North, New Zealand) for statistical analysis. The authors have not stated any conflicts of interest.

\section{REFERENCES}

Aharoni, Y., A. Orlov, A. Brosh, R. Granit, and J. Kanner. 2005. Effects of soybean oil supplementation of high forage fattening diet on fatty acid profiles in lipid depots of fattening bull calves, and their levels of blood vitamin E. Anim. Feed Sci. Technol. 119:191202. https://doi.org/10.1016/j.anifeedsci.2005.01.002.

Alomar, D., R. Fuchslocher, and S. Stockebrand. 1999. Effects of ovenor freeze-drying on chemical composition and NIR spectra of pasture silage. Anim. Feed Sci. Technol. 80:309-319. https://doi.org/ 10.1016/S0377-8401(99)00053-X.

AOAC International. 2012. Official Methods of Analysis. 19th ed. AOAC International, Gaithersburg, MD.

Attwood, G. T., A. V. Klieve, D. Ouwerkerk, and B. K. C. Patel. 1998. Ammonia-hyperproducing bacteria from New Zealand ruminants. Appl. Environ. Microbiol. 64:1796-1804.

Banni, S., G. Carta, E. Angioni, E. Murru, P. Scanu, M. P. Melis, D. E. Bauman, S. M. Fischer, and C. Ip. 2001. Distribution of conjugated linoleic acid and metabolites in different lipid fractions in the rat liver. J. Lipid Res. 42:1056-1061.

Bayat, A. R., I. Tapio, J. Vilkki, K. J. Shingfield, and H. Leskinen. 2018. Plant oil supplements reduce methane emissions and improve milk fatty acid composition in dairy cows fed grass silage-based diets without affecting milk yield. J. Dairy Sci. 101:1136-1151. https://doi.org/10.3168/jds.2017-13545.
Beauchemin, K. A., M. Kreuzer, F. O'Mara, and T. A. McAllister. 2008. Nutritional management for enteric methane abatement: A review. Aust. J. Exp. Agric. 48:21-27. https://doi.org/10.1071/ EA07199.

Beechey-Gradwell, Z. D., S. Winichayakul, and N. J. Roberts. 2018. High lipid perennial ryegrass growth under variable nitrogen, water and carbon dioxide supply. Pages 49-54 in Proc. NZ Grassland Assoc. 80. New Zealand Grassland Society Inc., Dunedin, New Zealand.

Benjamini, Y., and Y. Hochberg. 1995. Controlling the false discovery rate: A practical and powerful approach to multiple testing. J. R. Stat. Soc. Series B Stat. Methodol. 57:289-300. https://doi.org/10 .1111/j.2517-6161.1995.tb02031.x.

Browse, J., P. J. McCourt, and C. R. Somerville. 1986. Fatty acid composition of leaf lipids determined after combined digestion and fatty acid methyl ester formation from fresh tissue. Anal. Biochem. 152:141-145. https://doi.org/10.1016/0003-2697(86)90132-6.

Buxton, D. R., and P. O'Kiely. 2003. Preharvest plant factors affecting ensiling. Silage Sci. Technol. 42:199-250.

Cherney, J., and D. Cherney. 2003. Assessing silage quality. Silage Sci. Technol. 42:141-198.

Conover, W. J. 1999. Practical Nonparametric Statistics. 3rd ed. John Wiley \& Sons Inc., Edison, NJ.

Dewhurst, R., K. Shingfield, M. Lee, and N. Scollan. 2006. Increasing the concentrations of beneficial polyunsaturated fatty acids in milk produced by dairy cows in high-forage systems. Anim. Feed Sci. Technol. 131:168-206. https://doi.org/10.1016/j.anifeedsci.2006 .04 .016 .

Dohme, F., A. Machmuller, A. Wasserfallen, and M. Kreuzer. 2001. Ruminal methanogenesis as influenced by individual fatty acids supplemented to complete ruminant diets. Lett. Appl. Microbiol. 32:47-51. https://doi.org/10.1046/j.1472-765x.2001.00863.x.

Dong, Y., H. Bae, T. McAllister, G. Mathison, and K. Cheng. 1997. Lipid-induced depression of methane production and digestibility in the artificial rumen system (RUSITEC). Can. J. Anim. Sci. 77:269-278. https://doi.org/10.4141/A96-078.

Doreau, M., and A. Ferlay. 1994. Digestion and utilization of fatty acids by ruminants. Anim. Feed Sci. Technol. 45:379-396. https:/ /doi.org/10.1016/0377-8401(94)90039-6.

Field, C. J., H. H. Blewett, S. Proctor, and D. Vine. 2009. Human health benefits of vaccenic acid. Appl. Physiol. Nutr. Metab. 34:979-991. https://doi.org/10.1139/H09-079.

France, J., and J. Dijkstra. 2005. Volatile fatty acid production. Pages157-176 in Quantitative Aspects of Ruminant Digestion and Metabolism. 2nd ed. J. Dijkstra, J. M. Forbes, and J. France, ed. CABI publishing, Wallingford, UK.

Ghazani, S. M., and A. G. Marangoni. 2016. Healthy fats and oils. Pages 257-267 in Encyclopaedia of Food Grains. 2nd ed. C. Wrigley, H. Corke, K. Seetharaman, and J. Faubion, ed. Oxford Academic Press, Oxford, UK.

Glasser, F., M. Doreau, G. Maxin, and R. Baumont. 2013. Fat and fatty acid content and composition of forages: A meta-analysis. Anim. Feed Sci. Technol. 185:19-34. https://doi.org/10.1016/j .anifeedsci.2013.06.010.

Guyader, J., M. Eugène, B. Meunier, M. Doreau, D. P. Morgavi, M. Silberberg, Y. Rochette, C. Gerard, C. Loncke, and C. Martin. 2015. Additive methane-mitigating effect between linseed oil and nitrate fed to cattle. J. Anim. Sci. 93:3564-3577. https://doi.org/ 10.2527/jas.2014-8196.

Halmemies-Beauchet-Filleau, A., P. Kairenius, S. Ahvenjärvi, L. K. Crosley, S. Muetzel, P. Huhtanen, A. Vanhatalo, V. Toivonen, R. J. Wallace, and K. J. Shingfield. 2013. Effect of forage conservation method on ruminal lipid metabolism and microbial ecology in lactating cows fed diets containing a 60:40 forage-to-concentrate ratio. J. Dairy Sci. 96:2428-2447. https://doi.org/10.3168/jds .2012-6043.

Haque, M. N. 2018. Dietary manipulation: A sustainable way to mitigate methane emissions from ruminants. J. Anim. Sci. Technol. 60:15. https://doi.org/10.1186/s40781-018-0175-7. 
Harfoot, C., and G. Hazlewood. 1997. Lipid metabolism in the rumen. Pages 382-426 in The Rumen Microbial Ecosystem. P. N. Hobson and C. S. Stewart, ed. Springer, Dordrecht, the Netherlands.

Henderson, G., F. Cox, S. Ganesh, A. Jonker, W. Young, P. H. Janssen, Global Rumen Census Collaborators. 2015. Rumen microbial community composition varies with diet and host, but a core microbiome is found across a wide geographical range. Sci. Reports 5:14567. https://doi.org/10.1038/srep14567.

Hoedtke, S., and A. Zeyner. 2011. Comparative evaluation of laboratory-scale silages using standard glass jar silages or vacuum-packed model silages. J. Sci. Food Agric. 91:841-849. https://doi.org/10 $.1002 /$ jsfa. 4255.

Holden, L. A., L. D. Muller, G. A. Varga, and P. J. Hillard. 1994. Ruminal digestion and duodenal nutrient flows in dairy cows consuming grass as pasture, hay, or silage. J. Dairy Sci. 77:3034-3042. https://doi.org/10.3168/jds.S0022-0302(94)77245-3.

Jaakkola, S., and P. Huhtanen. 1993. The effects of forage preservation method and proportion of concentrate on nitrogen digestion and rumen fermentation in cattle. Grass Forage Sci. 48:146-154. https: //doi.org/10.1111/j.1365-2494.1993.tb01847.x.

Jalč, D., A. Lauková, Z. Váradyová, P. Homolka, and V. Koukolová. 2009. Effect of inoculated grass silages on rumen fermentation and lipid metabolism in an artificial rumen (RUSITEC). Anim. Feed Sci. Technol. 151:55-64. https://doi.org/10.1016/j.anifeedsci.2008 .11.004.

Jalč, D., A. Potkanski, M. Szumacher-Strabel, J. Kowalczyk, and A. Cieslak. 2006. The effect of a high forage diet and different oil blends on rumen fermentation in vitro. J. Anim. Feed Sci. 15(Suppl. 1):141-144. https://doi.org/10.22358/jafs/70429/2006.

Jenkins, T. C. 1993. Lipid metabolism in the rumen. J. Dairy Sci. 76:3851-3863. https://doi.org/10.3168/jds.S0022-0302(93)77727 -9 .

Jenkins, T. C., and W. C. Bridges. 2007. Protection of fatty acids against ruminal biohydrogenation in cattle. Eur. J. Lipid Sci. Technol. 109:778-789. https://doi.org/10.1002/ejlt.200700022.

Jermyn, M. A. 1956. New method for determining ketohexoses in the presence of aldohexoses. Nature 177:38-39. https://doi.org/10 $1038 / 177038 \mathrm{a} 0$

Johnson, K. A., and D. E. Johnson. 1995. Methane emissions from cattle. J. Anim. Sci. 73:2483-2492. https://doi.org/10.2527/1995 $.7382483 \mathrm{x}$

Kong, Y., M. He, T. McAlister, R. Seviour, and R. Forster. 2010a. Quantitative fluorescence in situ hybridization of microbial communities in the rumens of cattle fed different diets. Appl. Environ. Microbiol. 76:6933-6938. https://doi.org/10.1128/AEM.00217-10.

Kong, Y., R. Teather, and R. Forster. 2010b. Composition, spatial distribution, and diversity of the bacterial communities in the rumen of cows fed different forages. FEMS Microbiol. Ecol. 74:612-622. https://doi.org/10.1111/j.1574-6941.2010.00977.x.

Lim, J.-N., J.-J. Oh, T. Wang, J.-S. Lee, S.-H. Kim, Y.-J. Kim, and H.G. Lee. 2014. trans-11 18:1 Vaccenic acid (TVA) has a direct anticarcinogenic effect on MCF-7 human mammary adenocarcinoma cells. Nutrients 6:627-636. https://doi.org/10.3390/nu6020627.

Lourenço, M., E. Ramos-Morales, and R. Wallace. 2010. The role of microbes in rumen lipolysis and biohydrogenation and their manipulation. Animal 4:1008-1023. https://doi.org/10.1017/ S175173111000042X.

Mauricio, R. M., F. L. Mould, M. S. Dhanoa, E. Owen, K. S. Channa, and M. K. Theodorou. 1999. A semi-automated in vitro gas production technique for ruminant feedstuff evaluation. Anim. Feed Sci. Technol. 79:321-330. https://doi.org/10.1016/S0377 -8401(99)00033-4.

McKain, N., K. J. Shingfield, and R. J. Wallace. 2010. Metabolism of conjugated linoleic acids and 18:1 fatty acids by ruminal bacteria: Products and mechanisms. Microbiology (Reading, Engl.) 156:579-588. https://doi.org/10.1099/mic.0.036442-0.

Menke, K. H., L. Raab, A. Salewski, H. Steingass, D. Fritz, and W. Schneider. 1979. The estimation of the digestibility and metabolizable energy content of ruminant feeding stuffs from the gas pro- duction when they are incubated with rumen liquor in vitro. J. Agric. Sci. 93:217-222. https://doi.org/10.1017/S0021859600086305.

Mohammed, R., C. S. Stanton, J. J. Kennelly, J. K. G. Kramer, J. F. Mee, D. R. Glimm, M. O'Donovan, and J. J. Murphy. 2009. Grazing cows are more efficient than zero-grazed and grass silage-fed cows in milk rumenic acid production. J. Dairy Sci. 92:3874-3893. https://doi.org/10.3168/jds.2008-1613.

Mould, F., K. Kliem, R. Morgan, and R. Mauricio. 2005. In vitro microbial inoculum: A review of its function and properties. Anim. Feed Sci. Technol. 123:31-50. https://doi.org/10.1016/j.anifeedsci 2005.04.028.

Muetzel, S., C. Hunt, and M. H. Tavendale. 2014. A fully automated incubation system for the measurement of gas production and gas composition. Anim. Feed Sci. Technol. 196:1-11. https://doi.org/ 10.1016/j.anifeedsci.2014.05.016.

Naoki, N., and T. Yuji. 2008. Variations in bacterial communities in laboratory-scale and big bale silos assessed by fermentation products, colony counts and denaturing gradient gel electrophoresis profiles. Lett. Appl. Microbiol. 46:283-288. https://doi.org/10 $.1111 / \mathrm{j} .1472-765$ X.2007.02306.x.

Paillard, D., N. McKain, L. C. Chaudhary, N. D. Walker, F. Pizette, I. Koppova, N. R. McEwan, J. Kopečný, P. E. Vercoe, P. Louis, and R. J. Wallace. 2007. Relation between phylogenetic position, lipid metabolism and butyrate production by different Butyrivibrio-like bacteria from the rumen. Antonie Van Leeuwenhoek 91:417-422. https://doi.org/10.1007/s10482-006-9121-7.

Pellikaan, W. F., W. H. Hendriks, G. Uwimana, L. J. G. M. Bongers, P. M. Becker, and J. W. Cone. 2011. A novel method to determine simultaneously methane production during in vitro gas production using fully automated equipment. Anim. Feed Sci. Technol. 168:196-205. https://doi.org/10.1016/j.anifeedsci.2011.04.096.

Rasmussen, J., and A. Harrison. 2011. The benefits of supplementary fat in feed rations for ruminants with particular focus on reducing levels of methane production. ISRN Vet. Sci. 2011:613172. https:/ /doi.org/10.5402/2011/613172.

Richardson, A. J., A. G. Calder, C. S. Stewart, and A. Smith. 1989. Simultaneous determination of volatile and non-volatile acidic fermentation products of anaerobes by capillary gas chromatography. Lett. Appl. Microbiol. 9:5-8. https://doi.org/10.1111/j.1472-765X 1989.tb00278.x.

Roberts, N. J., R. W. Scott, S. Winichayakul, and M. Roldan. 2015. U.S. Patent No 8987551 B2, AgResearch Limited.

Seale, D. R., A. Henderson, K. O. Pettersson, and J. F. Lowe. 1986. The effect of addition of sugar and inoculation with two commercial inoculants on the fermentation of lucerne silage in laboratory silos. Grass Forage Sci. 41:61-70.

Sharp, R., P. Hooper, and D. Armstrong. 1994. The digestion of grass silages produced using inoculants of lactic acid bacteria. Grass Forage Sci. 49:42-53. https://doi.org/10.1111/j.1365-2494.1994 .tb01975.x.

Shingfield, K. J., M. Bonnet, and N. Scollan. 2013. Recent developments in altering the fatty acid composition of ruminant-derived foods. Animal 7(Suppl. 1):132-162. https://doi.org/10.1017/ S1751731112001681.

Toral, P. G., F. J. Monahan, G. Hervás, P. Frutos, and A. P. Moloney. 2018. Review: Modulating ruminal lipid metabolism to improve the fatty acid composition of meat and milk. Challenges and opportunities. Animal 12(Suppl. 2):s272-s281. https://doi.org/10 $.1017 /$ S1751731118001994.

Ueda, K., A. Ferlay, J. Chabrot, J. Loor, Y. Chilliard, and M. Doreau. 2003. Effect of linseed oil supplementation on ruminal digestion in dairy cows fed diets with different forage: Concentrate ratios. J. Dairy Sci. 86:3999-4007. https://doi.org/10.3168/jds.S0022 $-0302(03) 74011-9$

Vanhercke, T., A. El Tahchy, Q. Liu, X.-R. Zhou, P. Shrestha, U. K. Divi, J.-P. Ral, M. P. Mansour, P. D. Nichols, C. N. James, P. J. Horn, K. D. Chapman, F. Beaudoin, N. Ruiz-Lopez, P. J. Larkin, R. C. de Feyter, S. P. Singh, and J. R. Petrie. 2014. Metabolic engineering of biomass for high energy density: Oilseed-like triacyl- 
glycerol yields from plant leaves. Plant Biotechnol. J. 12:231-239. https://doi.org/10.1111/pbi.12131.

Vargas, J. E., S. Andrés, T. J. Snelling, L. López-Ferreras, D. R. Yáñez-Ruíz, C. García-Estrada, and S. López. 2017. Effect of sunflower and marine oils on ruminal microbiota, in vitro fermentation and digesta fatty acid profile. Front. Microbiol. 8:1124. https: //doi.org/10.3389/fmicb.2017.01124.

Veneman, J. B., S. Muetzel, K. J. Hart, C. L. Faulkner, J. M. Moorby, H. B. Perdok, and C. J. Newbold. 2015. Does dietary mitigation of enteric methane production affect rumen function and animal productivity in dairy cows? PLoS One 10:e0140282. https://doi .org/10.1371/journal.pone.0140282.

Wang, L., G. Zhang, H. Xu, H. Xin, and Y. Zhang. 2019. Metagenomic analyses of microbial and carbohydrate-active enzyme in the rumen of Holstein cows fed different forage-to-concentrate ratios. Front. Microbiol. 10:649. https://doi.org/10.3389/fmicb.2019 .00649 .

Weatherburn, M. W. 1967. Phenol-hypochlorite reaction for determination of ammonia. Anal. Chem. 39:971-974. https://doi.org/10 $.1021 /$ ac60252a045.
Winichayakul, S., R. Cookson, R. Scott, J. Zhou, X. Zou, K. Roldan, K. Richardson, and N. Roberts. 2008. Delivery of grasses with high levels of unsaturated, protected fatty acids. Pages 211-216 in Proc. NZ Grassland Assoc. 70. New Zealand Grassland Society Inc., Dunedin, New Zealand.

Winichayakul, S., R. W. Scott, M. Roldan, J.-H. B. Hatier, S. Livingston, R. Cookson, A. C. Curran, and N. J. Roberts. 2013. In vivo packaging of triacylglycerols enhances Arabidopsis leaf biomass and energy density. Plant Physiol. 162:626-639. https://doi.org/ $10.1104 /$ pp.113.216820.

Zhao, L., Q. Meng, L. Ren, W. Liu, X. Zhang, Y. Huo, and Z. Zhou. 2015. Effects of nitrate addition on rumen fermentation, bacteria biodiversity and abundance. Asian-Australas. J. Anim. Sci. $28: 1433-1441$

\section{ORCIDS}

S. Winichayakul @ https://orcid.org/0000-0003-2721-5071 